\title{
Liebe Politiker, redet doch mal mit uns!
}

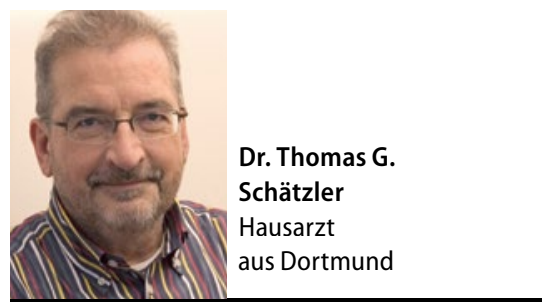

\section{Nach der Wahl stehen die Chancen für sinnvolle Gesundheitsreformen schlecht. Die Experten der Parteien sprechen nicht mit Kranken und Ärzten. Der Zwischenruf eines streitbaren Hausarztes.} \begin{abstract}
ist eine unangemessene Sichtweise, Krankheit nur und ausschließlich auf Umwelteinwirkungen, Fehlverhalten von Patienten, das Versagen von Primärprävention, Vorsorge- und Früherkennungsdefizite bzw. auf Fehl- und Falschbehandlung oder mangelnde ärztlich-therapeutische Kunst zurückzufüh-
\end{abstract}

Überwiegend medizin- und versorgungsferne Experten konfabulieren am Thema vorbei über Abwesenheit von Krankheit, Gesundheit, bio-psycho-soziales Dauer-Wohlbefinden, gesunde Lebensweise und erfolgreiche Prävention. Das grenzt nicht nur unsere auf Dauer chronisch Kranken, sondern auch unsere z.T. kommunikationsdefizitären und verhaltensveränderten Patienten aus. Es
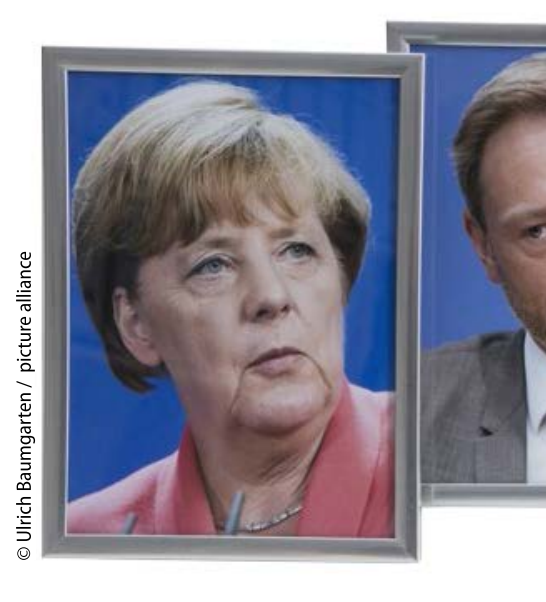

Leistungskurs bekannte Gerechtigkeitslücke in der GKV: die Beitragsbemessungsgrenze. Es erstaunt, dass Fachpolitiker das offenkundig nicht wissen selbst Kollegen wie Karl Lauterbach (SPD) und Harald Terpe (Grüne).

Arbeitnehmer haben einen GKV-Beitragssatz von 7,3\%, Einkünfte oberhalb der Grenze von 4.350 Euro monatlich
Jahr. Den modernen Entwicklungen der personalisierten und hochtechnisierten Medizin wurde sie nie angepasst. Doch auch die jährlichen Punktwert-Anhebungen in der GKV liegen mit zuletzt gut $1 \%$ seit Jahren unterhalb von Inflation und Lohnsummenzuwächsen.

Unter einer Jamaika-Koalition werden sich die Chancen für eine GOÄ-Novellierung erneut verschlechtern: $\mathrm{Zu}$ viele parteipolitische Partikularinteressen und ein genereller „ÄrzteHasser"-Kult werden m.E. die Reform auf längere Sicht beerdigen. Die hausarztzentrierte Medizin - oder zutreffender: die Familienmedizin - hat entgegen allen parteipoli-

Perspektivisch muss Chancen- und Risikoverteilungen, Krankheit, Traumata, bio-psycho-soziale Deprivation, Gesundheit, Glück, Freude, Trauer und Tod sind Legierungen unseres Lebens.

Was mich beim Wahlergebnis freut: Drei Parteien unter Führung der SPD haben mit ihrer "Gerechtigkeitslücke“ bezüglich GKV und PKV und ihrer damit verbundenen, altklugen Forderung nach einer Bürgerversicherung nicht punkten können. Immerhin besteht seit Jahrzehnten eine reale, jedem SoWi- werden aber beitragsfrei gestellt. Man zahlt also maximal 317,55 Euro ohne Zusatzbeitrag. Wer 10.000 Euro brutto verdient, zahlt somit nur 3,18\% und ist komplett familienversichert.

\section{PKV und GKV koexistieren gut}

Aus ärztlicher Sicht frage ich mich, was an einer friedlichen Koexistenz von GKV und PKV denn auszusetzen ist? Es ärgert allenfalls, dass die privatärztliche Gebührenordnung seit 1983 um ganze $14 \%$ gesteigert wurde - das sind $0,4 \%$ pro tischen Beteuerungen keine Lobby.

Ärzte-Bashing als sich die Gesundheits- in eine Krankheitspolitik transformieren. Alle anderen Themen wie E-Health, Telemedizin, Digitalisierung bei der Krankheitsbewältigung und -versorgung, auch die sogenannte „Health Literacy“, unterliegen dem Primat der Medizin. Forschung und Wissenschaft müssen wieder in den Dienst der Kranken, Leidenden und an der bio-psycho-sozialen Teilhabe Behinderten gestellt werden.

- Der Autor ist Facharzt für Allgemeinmedizin in Dortmund 